\title{
BRAINSTORMING BUSINESS MODEL CANVAS PADA FORMULASI STRATEGI "RABUK DIYANG" SEBAGAI PRODUK KHAS KABUPATEN INDRAGIRI HILIR
}

\author{
Roberta Zulfhi Surya ${ }^{1}$, Rosliana² \\ ${ }^{1}$ Program Studi Teknik Industri, Universitas Islam Indragiri \\ ${ }^{2}$ Program Studi Akuntansi, Universitas Islam Indragiri \\ Email: robertazulfhi@yahoo.co.id (korespondensi)
}

\begin{abstract}
This research uses integrating brainstorming method and Business Model Canvas, model is done with brainstorming method. The Canvas Business Model covers nine blocks, Customer Relationships, Key Partners, Value Propositions, Customer Segments, and cash flow, key resources (key resources), key activities (key activities) and cost structures (cost structures). The result of the research shows strategy with Business Model Canvas can effectively and efficiently in determining Rabuk Diang Empowerment Group strategy
\end{abstract}

Keywords: Brainstorming, Business Model Canvas, nine blocks

\section{Abstrak}

Penelitian ini menggunakan metode Brainstrorming dan Business Model Canvas. Model disusun dengan menggali ide dan gagasan dengan metode brainstorming. Business Model Canvas meliputi sembilan blok, yaitu Customer Relationships (hubungan pelanggan), Key Partners (kemitraan utama), Value Propositions (proporsi nilai), Customer Segments (segmen pelanggan) dan Channel (saluran), revenue stream (arus pendapatan), key resources (sumber daya utama), key activities (aktivitas kunci) dan cost structure (struktur biaya). Hasil penelitian menunjukkan strategi dengan Business Model Canvas dapat secara efektif dan efisien dalam penentuan strategi Kelompok yang diberdayakan Rabuk Diyang.

Kata kunci: Brainstorming, Kanvas Bisnis Model, sembilan blok

\section{Pendahuluan}

Sumberdaya perikanan laut Kabupaten Indragiri Hilir menjadi salah satu faktor penunjang ekonomi utama masyarakat khususnya didaerah pesisir seperti Mandah, Tanah Merah, Kuala Indragiri, Kateman, Concong dan Reteh. Kabupaten ini mempunyai luas wilayah $\pm 18.812 .97 \mathrm{Km} 2$ yang terdiri dari $11.606 \mathrm{Km} 2$ luas daratan. $6.318 \mathrm{Km} 2$ perairan laut, 888,97 km2 perairan umum dengan panjang garis pantai $339,5 \mathrm{~km}$. sepanjang garis pantai diperkirakan mencapai 129.455,56 Ha. Dengan daerah yang cukup luas Kabupaten Indragiri Hilir tentu memiliki berbagai macam jenis flora dan fauna, Dari berbagai ekosistem tersebut, terkandung keragaman fauna akuatik yang tinggi, yang sebagian besar memiliki potensi ekonomi yang bernilai tinggi

Peningkatan value added untuk produk perikanan perlu diberikan karena berbagai faktor seperti daya tahan, nilai ekonomi, dan kelestarian sumberdaya laut. Hasil laut yang ditangkap oleh nelayan biasanya dijual dalam bentuk ikan basah, ikan kering dan produk olahan seperti kerupuk, aplang, abon, dan lainnya. Namun, dikarenakan minimnya pengetahuan, modal, dan akses pasar membuat produksi produk olahan tidak begitu bergairah.

Rabuk Diyang adalah salah satu produk olahan hasil laut berbentuk Abon dengan khas bumbu suku Banjar. Konsep produksi Rabuk Diyang adalah pemberdayaan terhadap ibu-ibu yang tidak berpenghasilan tetap di Desa Tanah Merah, Kabupaten Indragiri Hilir. Dikarenakan berbagai faktor seperti kemampuan produksi, legalitas, dan pemasaran, Rabuk Diyang saat ini masih dipasarkan secara terbatas. Konsumen pelanggan Rabuk Diyang adalah ASN di Bappedalitbang Provinsi Riau.

Pada penelitian ini akan Business Medel Canvas Rabuk Diyang agar dapat meningkatkan pangsa pasar dan skala produksi sehingga akan memberikan efek domino terhadap kesejahteraan anggota.

Rabuk sering dikenal dengan Abon yang terbuat dari ikan. Rabok Diyang terbuat dari daging ikan Lomek (Harpodan Neherous) sebagai bahan baku utama. Rabok Diyang telah diproduksi sejak Maret 2019 di Lorong Melati Desa 
Tanah Merah Kecamatan Tanah Merah. Produksi Rabok Diyang dengan memberdayakan ibu-ibu yang tidak memiliki penghasilan tetap. Saat ini Rabok Diyang dipasarkan dengan menggunakan direct marketing, Media Sosial dan e-commerse Shopee. Dengan terbatasnya sumberdaya dan legalitas yang dimiliki, Rabuk Diyang masih stagnant melayani permintaan pasar terbatas. Pemberdayaan Perempuan untuk produksi Rabuk Diyang dilaksanakan oleh ibu Lina Nasrun dengan menggelontorkan modal pribadi untuk produksi dan pemasaran Rabuk Diyang. Hasil penjualan Rabok Diyang diserahkan sepenuhnya kepada ibu-ibu yang terlibat sebagai sumber penghasilan mereka.

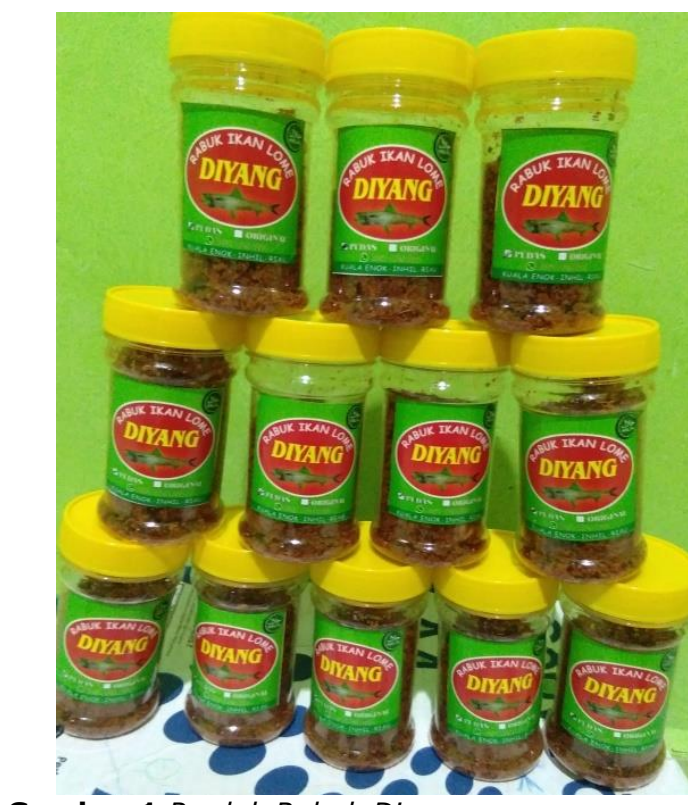

Gambar 1 Produk Rabuk Diyang

\section{TINJAUAN PUSTAKA}

\subsection{Brainstorming}

Brainstorming dapat untuk mendapatkan banyak ide dari sekelompok manusia dalam waktu yang sangat singkat. Brainstorming biasanya merupakan aktivitas kelompok yang menghasilkan sejumlah besar ide. Sekelompok manusia tidak hanya akan saling melengkapi dalam pengalaman yang luas, tetapi juga menjamin pertukaran ide dan saling mengisi. Dalam hal demikian, ide seseorang akan menolong merangsang ide orang lain dan akhirnya menjadi arus ide yang nyata. Metode kreatif terdiri dari dua metode yaitu Brainstorming dan sinektik. Brainstorming merupakan metode kreatif untuk perancangan produk dengan menghasilkan sebanyak mungkin ide-ide kreatif secara spontan. Untuk penggunaan yang efektif Brainstorming digunakan berkelompok sebagai teknik untuk meningkatkan kreativitas dan menghasilkan berbagai macam ide. Brainstorming dapat membantu sekelompok orang (terdiri dari 7-8 orang) untuk menghasilkan ide-ide baru yang terinspirasi dari ide yang telah ada di dapatkan sebelumnya [1].

Brainstorming mampu membantu tim kerja memecahkan masalah dengan solusi yang inovatif, memperoleh keuntungan dari berbagai ide orang lain yang bersifat mengembangankan ataupun membangun hubungan antar siswa maupun menilai pandangan antar tim. kelebihan metode brainstorming diantaranya yaitu: membangun pengetahuan, meningkatkan kemampuan mental dan membantu tim dalam belajar dengan tanpa ada kritik, aturan atau evaluasi dalam pembatasan pembatasan menghasilkan ide. kelebihan teknik brainstorming bagi guru yaitu adanya curah pendapat ia dapat berkesempatan memberikan masalah dan meminta tim memberi saran sebanyak mungkin dalam periode singkat guna meningkatkan fluency. Bagi tim yaitu siswa berkesempatan untuk mencoba, megamati, berasumsi, menilai hingga menyimpulkan [2].

Hambatan dalam pelaksanaan metode brainstorming meliputi adanya kemalasan sosial dan kemalasan karena persepsi mengakibatkan, kesadaran tanggung jawab pribadi, mengurangi konstribusi individu, anggota yang menyerah mengakibatkan minimnya kinerja kelompok, kelompok mendorong hanya satu orang yang berbicara. Selain itu, terdapat faktor interpersonal yang meliputi komitmen individu, karakteristik kepribadian, keragaman gaya kognitif, perbedaan gender, budaya, waktu yang dihabiskan dan kualitas interaksi dan menurunya tujuan pribadi karena antisipasinya merasa bahwa yang lain telah melakukan hal yang sama. Hambatan produktivitas kelompok bisa terjadi karena adanya penyerahan terhadap kelompok, penghakiman yang tidak tepat dan membatasi interaksi [2]. [3]:

Tahapan metode brainstorming mencakup

a. preparation (persiapan),

b. fact - finding (pencarian fakta),

c. warm up (pemanasan),

d. idea finding (pencarian ide),

e. solution finding (pencarian solusi),

f. implementation (pelaksanaan),

Langkah-langkah dalam sesi brainstorming yaitu [2]

a. pemanasan yang bertujuan untuk menarik perhatian peserta

b. memperoleh ide bertujuan untuk mengetahui apa yang peserta fikirkan dari topik pembelajaran disertai perbedaan ide,

c. menulis di papan bertujuan untuk mengeluarkan pengetahuan peserta dengan cara melibatkannya secara sistematis dan terfokus dalam proses, 
d. menulis dan menyajikan ide / usulan: merangsang peserta untuk menuliskan informasi dan menampilkannya,

e. hindari frustasi bertujuan untuk mengerahkan semua peserta dengan mengumpulkan segala macam ide,

f. hindari kejenuhan bertujuan untuk menyatukan segala macam poin dan informasi dan mengintegrasikan pengetahuan dengan cara membuat sesi yang lebih menarik

\subsection{Business Model Canvas}

Business Model Canvas adalah sebuah model bisnis gambaran logis mengenai bagaimana sebuah organisasi menciptakan, menghantarkan dan menangkap sebuah nilai $[4 ; 5 ; 6]$. Canvas ini membagi business model menjadi 9 buah komponen utama, kemudian dipisahkan lagi menjadi komponen kanan (sisi kreatif) dan kiri (sisi logik). Persis seperti otak manusia. Ke sembilan komponen yang ada tersebut adalah sebagai berikut, (diurut dari kanan ke kiri). Customer Segment, Customer Relationship, Customer Channel, Revenue Structure, Value Proposition, Key Activities, Key Resource, Cost Structure, dan Key Partners.

a. Customer Segment (CS) yaitu menentukan segmen target customer dari bisnis yang akan dikembangkan. Posisikan diri pada sisi customer untukmemperhatikan apa yang dilihat, didengar, dipikirkan dan dilakukan, menjadi keinginan dan tujuan, rasa takut, dan harapan.

b. Value Proposition (VP) yaitu memperkirakan kebutuhan customer yang sudah diidentifikasi pada customer segment. Berdasarkan kebutuhan itu, selanjutnya dapat didefinisikan value (nilai) apa yang akan diberikan agar mampu memenuhi kebutuhan customer. Value yang diberikan itu akan menjadi nilai inti dari kegiatan bisnis.

c. Customer Relationship (CR) yaitu mendefinisikan hubungan antara perusahaan dan customer. Macam-macam jenis hubungan mulai dari memberikan bantuan personal perorangan kepada setiap customer, dengan memanfaatkan komunitas, atau bahkan berupa 'selfservice', yaitu tidak berhubungan langsung dengan customer.

d. Channel $(\mathrm{CH})$ yaitu cara untuk mencapai customer. Channel ini adalah jalur antara perusahaan dengan customer, bagaimana delivery dari value yang diberikan akan mampu mencapai customer dengan baik.

e. Revenue Stream (RS) yaitu representasi dari jalur penerimaan uang yang akan diterima dari setiap customer segment. Definisikan cara tertentu untuk menghasilkan revenue dari setiap customer segment. f. Key Resource (KR) adalah Sumber Daya Utamayang menjelaskan mengenai aset terpenting yang diperlukan dalam membuat model bisnis kerja. Setiap model bisnis memerlukan Sumber Daya Utama. Sumber Daya Utama akan memungkinkan perusahaan untuk membuat dan melebihi Proposisi Nilai, mencapai pasar, memelihara hubungan denganSegmenPelanggan, dan memperoleh pendapatan.

g. Key Activities (KA) adalah Kegiatan Utama yang menjelaskan hal terpenting yaitu perusahaan harus membuat model bisnis. Setiap model bisnis dibuat untuk sejumlah Kegiatan Utama. Hal ini merupakan tindakan yang paling penting bagi perusahaan sehingga harus maksimal untuk dapat menghasilkan operasi yang berhasil. Seperti Kunci Sumber Daya, diwajibkan untuk membuat dan melebihi Proposisi Nilai, Pencapaian pasar, mempertahankan Hubungan Pelanggan,dan pendapatan yang diperoleh, seperti Kunci Sumber Daya, kegiatan tergantung pada jenis model bisnis. Untuk perangkat lunak pembuat Microsoft,

h. Key Partners (KP) adalah Kunci Kemitraan yang menjelaskan jaringan pemasok dan mitra yang membuat pekerjaan model bisnis. Perusahaan menjalin kemitraan untuk banyak alasan, dan kemitraan menjadi landasan model bisnis. Perusahaan membentuk aliansi untuk mengoptimalkan model bisnisnya, mengurangi resiko, atau memperoleh sumber daya. Ada empat jeniskemitraan: • Strategi aliansi antara nonpesaing • Strategi kemitraan antara pesaing (Coopetition) • Usaha bersama: usaha untuk mengembangkan bisnis baru - Hubungan Pembeli-Pemasok untuk menjamin pasokan yang dapat diandalkan

i. Cost Structure adalah Struktur Biaya yang menggambarkan semua biaya yang dikeluarkan dalam mengoperasikan model bisnis ini. Blok bangunan ini menjelaskan biaya yang paling besar terjadi antara biayabiaya yang harus dikeluarkan untuk dapat menghasilkan Value Proposition yang ditujukan pada Customer Segments sehingga didapat Revenue Stream. Biaya tersebut dapat dihitung relatif mudah setelah mendefinisikan Sumber Daya Utama, Kegiatan Utama, dan Kunci Kemitraan.

\section{MetOdologi PENELITIAN}

Penggunaan brainstorming dalam penelitian ini dilakukan dengan cara mengumpulkan 9 orang peserta dengan range usia $20 \pm 3$ tahun dengan dari Program Studi Teknik Industri Universitas Islam Indragiri yang telah diberikan pemahaman tentang sistem produksi perikanan dan 
pengembangan produk. Dari berbagai masukan dan ide yang diperoleh melalui brainstorming, diinterpretasikan menjadi pernyataan kebutuhan konsumen. Selain itu brainstrorming juga melibatkan ibu Lina Nasrun sebagai Pemberdaya kelompok Rabuk Diyang.

Langkah selanjutnya adalah menyusun model dengan 9 blockbuilding canvas dengan menjaring ide dan gagasan dari peserta. Peserta memberikan ide dan gagasan dengan color sticky notes dengan mengisi setiap block dengan tidak ada sanggahan/debat dari peserta lain.

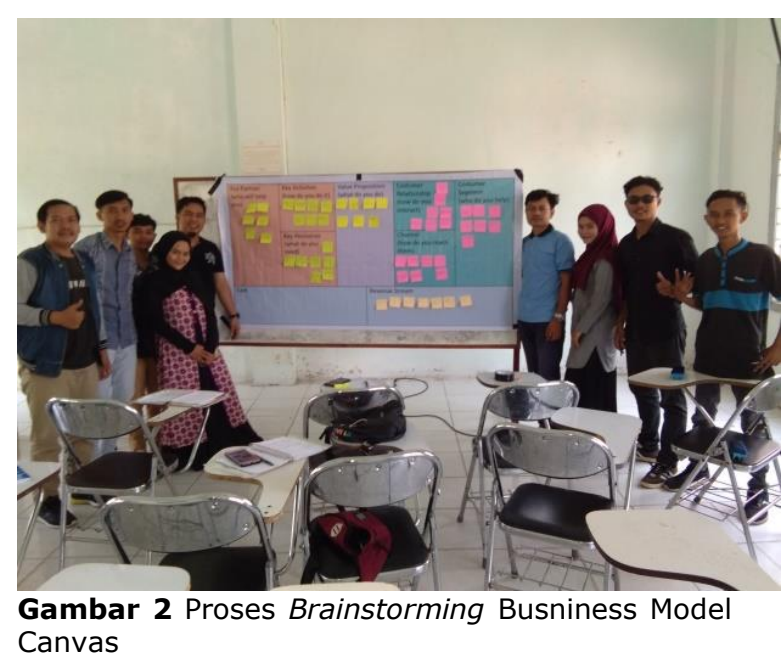

\section{HASIL PENELITIAN}

Dalam membuat pemetaan bisnis dengan Brainstorming Business Model Canvas yang menggali ide dan gagasan dari peserta dapat dilihat pada Business Model Canvas di bawah ini:

\begin{tabular}{|c|c|c|c|c|c|}
\hline $\begin{array}{l}\text { Key Partner } \\
\text { 1. Nelayan } \\
\text { sebagai } \\
\text { pemasok } \\
\text { bahan baku } \\
\text { 2.Penyedia } \\
\text { rempah } \\
\text { 3.e-commerse } \\
\text { 4.reseller }\end{array}$ & $\begin{array}{l}\text { Key Activities } \\
\text { 1. Memilih bahan } \\
\text { baku ikan segar } \\
\text { dan memastikan } \\
\text { ditangkap } \\
\text { dengan } \\
\text { memperhatikan } \\
\text { prinsip } \\
\text { sustainable, } \\
\text { misal tidak } \\
\text { diracun } \\
\text { 2. Produksi dengan } \\
\text { memperhatikan } \\
\text { prinsip } \\
\text { kebersihan } \\
\text { 3. Pemasaran } \\
\text { Key Resources } \\
\text { 1. SDM } \\
\text { 2. Modal } \\
\text { 3. Peralatan kerja }\end{array}$ & \multicolumn{2}{|c|}{$\begin{array}{l}\text { Value } \\
\text { Proposition } \\
\text { 1. Olahan ikan } \\
\text { segar } \\
\text { dengan rasa } \\
\text { khas; } \\
\text { 2. Bisa } \\
\text { dimakan } \\
\text { dimana saja } \\
\text { oleh siapa } \\
\text { saja; } \\
\text { 3. Terbuat dari } \\
\text { ikan segar } \\
\text { yang } \\
\text { langsung } \\
\text { didapat dari } \\
\text { nelayan } \\
\text { 4. Oleh-oleh } \\
\text { khas Inhil }\end{array}$} & $\begin{array}{l}\text { Costumer } \\
\text { Relationship } \\
\text { Membangun } \\
\text { interaksi } \\
\text { dengan } \\
\text { konsumen, } \\
\text { menggunakan } \\
\text { WhatApps, } \\
\text { Direct } \\
\text { Mesenger, Lite, } \\
\text { Shopee chat, dll }\end{array}$ & $\begin{array}{l}\text { Costumer } \\
\text { Segment } \\
\text { Segment pasar } \\
\text { premium } \\
\text { 1. Penyuka rasa } \\
\text { tradisional } \\
\text { 2. Menengah } \\
\text { keatas (PNS, } \\
\text { DOsen, } \\
\text { Pengusaha) }\end{array}$ \\
\hline \multicolumn{3}{|c|}{$\begin{array}{l}\text { Cost } \\
\text { Fix Cost : Pembelian Peralatan produksi, } \\
\text { packaging } \\
\text { Variable Cost : Bahan Baku (ikan dan } \\
\text { rempah), Jasa telekomunikasi }\end{array}$} & \multicolumn{3}{|c|}{$\begin{array}{l}\text { Revenue Stream } \\
\text { 1. Penjualan } \\
\text { 2. Cash Back Aplikasi }\end{array}$} \\
\hline
\end{tabular}

Gambar 3 Business Model Canvas

a. Value Proposition

Berdasarkan hasil brainstorming mengenai atribut yang dipentingkan oleh peserta yaitu:

$\checkmark$ Olahan ikan segar dengan rasa khas; $\checkmark$ Bisa dimakan dimana saja oleh siapa saja;

$\checkmark$ Terbuat dari ikan segar yang langsung didapat dari nelayan

$\checkmark$ Oleh-oleh khas Inhil 
Rabuk Diyang memberikan state of the art produknya adalah satu-satunya produk olahan ikan lomek(Harpodan Neherous) yang dapat dimakan oleh siapa saja dengan rasa khas suku Banjar dengan bahan baku ikan segar yang langsung diperoleh dari nelayan serta tidak melalui proses pengawetan sehingga memberikan citarasa yang lebih dibanding ikan yang telah diawetkan.

b. Customer Segments

Segmentasi merupakan kegiatan membagi pasar-pasar ke dalam kelompok pembeli yang berbeda, dimana masingmasing kelompok tersebut memiliki karakteristik yang sama. Segmentasi pasar konsumen dapat dilakukan berdasarkan geografis, demografis, psikografis dan perilaku konsumen [5]. Berdasarkan hasil brainstorming, sebagian besar segmen utama kalangan memengah ke atas yaitu PNS, Dosen dan pengusaha. Namun segmen kedua dapat ditarget adalah Penyuka rasa tradisional

c. Channel

Channel merupakan bagaimana cara produsen menggapai konsumen. Rabuk Diyang menggunakan 3 metode yaitu:

a. Direct marketing

b. Media Sosial (Facebook dan Instagram)

c. e-commerse (Shopee)

pemasaran lebih digencarkan menggunakan e-commerse. penggunaan e-commerse seperti Shoppe dan Lazada memberikan manfaat keluasan jaringan pemasaran yang dapat di akses seluruh dunia. Disisi lain dapat memudahkan konsumen dengan subsidi ongkos kirim.

\section{d. Costumer Relationship}

Costumer Relationship yaitu strategi membangun interaksi dengan konsumen, interaksi menggunakan WhatApps, Direct Mesenger, Lite, Shopee chat. Hal ini secara tidak langsung dapat mempererat hubungan antara perusahaan kepada konsumen secara personal.

e. Key Activities

Hasil dari brainstorming untuk block Key Activities yaitu:

$\checkmark$ Memilih bahan baku ikan segar dan memastikan ditangkap dengan memperhatikan prinsip sustainable. Pada industri pangan, bahan baku menentukan citarasa produk. Pemilihan bahan baku menjadi aktivitas utama untuk memastikan ikan yang ditangkap nelayan memperhatikan prinsip sustainable, yaitu proses penangkapan tidak menggunakan racun ikan, potasium atau bom ikan.

$\checkmark$ Produksi dengan memperhatikan prinsip kebersihan

$\checkmark$ Pemasaran

Selain memberikan produk yang sehat, berkualitas dan rasa yang enak, marketing merupakan key activities yang perlu diperhatikan. Yaitu dengan seluruh tim mengupload produk dan proses produksi ke sosial media masing-masing sehingga dapat mengedukasi konsumen.

\section{f. Key Partner}

Untuk menjamin keberlanjutan usaha Rabuk Diyang harus mempunyai jalinan kerja sama dengan partner yaitu:

$\checkmark$ Bahan baku yaitu Nelayan dan

Penyedia rempah

element bahan baku merupakan salah satu elemen penting dalam pelayanan. Dari sudut pandang finansial penggunaan bahan baku juga dapat mempengaruhi keuntungan yang di dapat perusahaan. Semakin rendah harga yang didapat dari hasil kerja sama, maka akan semakin besar juga keuntungan yang didapat.

$\checkmark$ Pemasaran yaitu e-commerse dan reseller

Dalam hal promosi, partner yang dapat dijalin kerja samanya adalah dengan Shopee dan reseller. Kedepannya, perlu dijajaki kerjasama dengan Pemerintah Daerah Kabupaten Indragiri Hilir untuk perizinan dan pemasaran.

g. Key Resources

Key resources yang utama disini adalah SDM, Peralatan kerja dan modal. SDM adalah semua partisipan yang memainkan peran dalam proses operasi Rabuk Diyang. Sebagian besar dipengaruhi oleh interaksi SDM dengan konsumennya. Karena jika interaksinya baik, konsumen juga akan puas dan menyampaikan kepada konsumen lain sehingga persepsi konsumen terhadap Rabuk Diyang tersebut sangat baik.

Sebagaimana dijelaskan di atas, Pemberdayaan Perempuan untuk produksi Rabok Diyang dilaksanakan oleh ibu Lina Nasrun dengan menggelontorkan modal 
pribadi untuk produksi dan pemasaran Rabok Diyang. Hasil penjualan Rabok Diyang diserahkan sepenuhnya kepada ibu-ibu yang terlibat sebagai sumber penghasilan mereka.

h. Revenue Stream

Revenue Stream utama dari Rabuk Diyang adalah dari Penjualan produk. Selain itu dikarenakan menggunakan aplikasi e-commerse yang telah memperoles star seller sehingga memiliki potensi untuk memperoleh Cash Back Aplikasi.

\section{i. Cost Structure}

Struktur biaya ditentukan dari key resources, key activities dan key partners dalam Business Model Canvas [5]. Biaya-biaya yang diperlukan untuk menciptakan value untuk customer yaitu:

$\checkmark$ Fix Cost : Pembelian Peralatan produksi, packaging

$\checkmark$ Variable Cost : Bahan Baku (ikan dan rempah), Jasa telekomunikasi

\section{KESIMPULAN DAN SARAN}

Dengan Business Model Canvas dapat disimpukan bahwa terdapat 9 area yang harus menjadi fokus strategi Rabuk Diyang. Value dari Rabuk Diyang harus menekankan pada produk premium yang mengedepankan khas citarasa, bahan baku yang mengedepankan prinsip sustainability serta dapat menjadi oleh-oleh khas Indragir Hilir. $\mathrm{Hal}$ ini berdasarkan dari segmentasi utama Rabuk Diyang yaitu PNS, Dosen dan Pengusaha yang menyukai citarasa khas. Penggunaan metode pemasaran e-commerse dapat menjangkau konsumen dimanapun berada. Untuk melakukan seluruh kegiatan yang berorientasi pada value yang diciptakan untuk konsumen potensial, Rabuk Diyang mengutamakan key resources pada sumber daya manusia professional yang menjaga kualitas produk meskipun hanya berasal dari kalangan menengah kebawah. Jaminan terhadap kualitas bahan baku yang ditangkap dengan prinsip sustainability yang tidak menggunakan racun ikan, potasiom maupun bom ikan.

Berdasarkan penelitian ini dapat dilihat bahwa Business Model Canvas dapat menjadi tools yang sederhana guna menghasilkan alternatif strategi Rabuk Diyang yang berujung pada peningkatan finansial. Namun penelitan berikutnya perlu dilakukan analisa SWOT, strategi pemasaran, dan strategi aliansi Rabuk Diyang agar dapat lebih berkembang.

Faktor Merk yang diberi nama Diyang dapat menggambarkan produk tersebut adalah citarasa suku Banjar. Kelemahan dari produk Rabuk Diyang adalah belum memiliki perizinan seperti PIRT dan sertifikat Halal. Dikarenakan Rabuk Diyang memiliki visi sebagai oleh-oleh khas Indragir Hilir, perlu menjalin kerjasama denga Pemerintah Daerah melalui Dinas Pariwisata, Dinas Koperasi dan UMKM serta Dekranasda.

\section{DAFTAR PUSTAKA}

[1] Darnianti dan Y. Sinambela, "Desain kursi kuliah dengan metode brainstorming di Fakultas Teknik Universitas Quality Medan" Yusnia Sinambela1 Juitech / Vol.02 / No. 02 / Oktober 2018

[2] A. Fauziah, "Penerapan Metode Brainstroming untuk meningkatkan kreatifitas siswa pada konsep pencemaran lingkungan di MA N Ciledug, [Skripsi], IAIN Cirebon, 2015

[3] A. Widowati,"Brainstorming sebagai alternatif berpikir kreatif dalam pembelajaran sains Biologi" Jurnal Biologi Edukasi 2(3), 17-22, 2010

[4] Osterwalder, Alexander dan Yves Pigneur,. Business Model Generation. John Willey \& Sons, Hoboken - NJ, 2010

[5] Dewobroto, "Penggunaan business model canvas sebagai dasar untuk menciptakan alternatif strategi bisnis dan kelayakan usaha" Jurnal Teknik Industri, ISSN:1411-6340, 2012

[6] Hartatik, T Baroto, "Strategi Pengembangan Bisnis Dengan Metode Business Model Canvas" Jurnal Teknik Industri, Vol. 18, No.02, Agustus 2017, pp. 113-120 ISSN 1978-1431 print / ISSN 2527-4112 online 


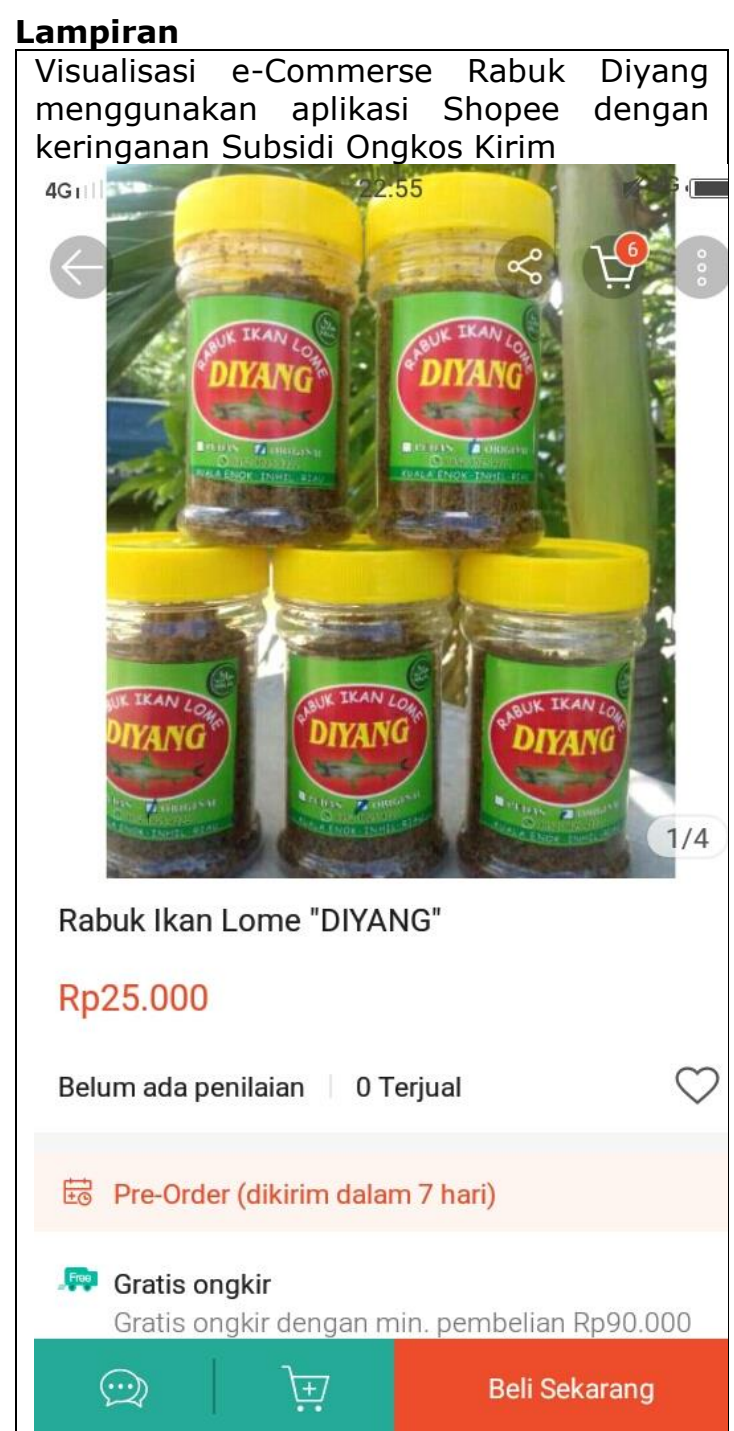

\section{Konsumen setia Rabuk Diyang}

Ibu Yulfatmi dan Ibu Nelita, PNS Bappeda Provinsi Riau

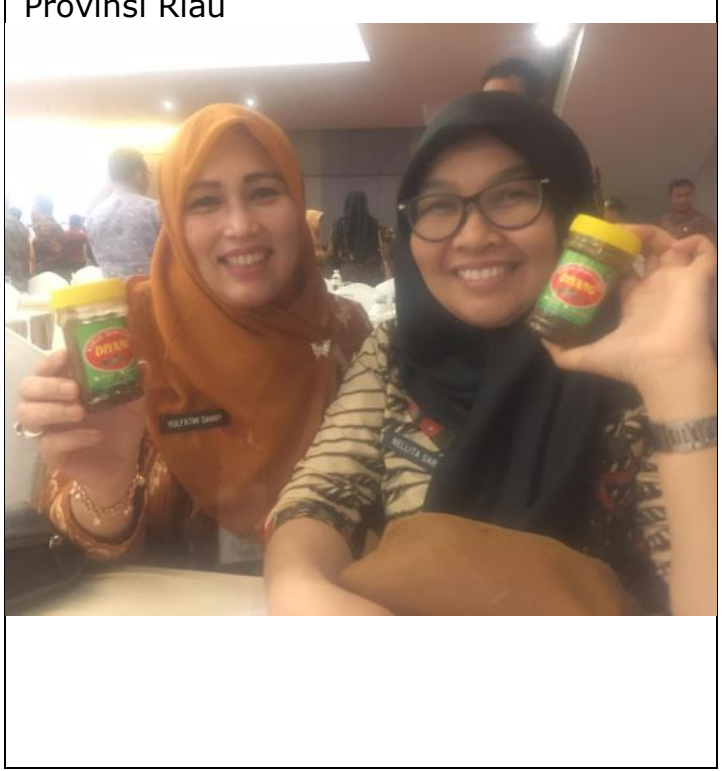

Memastikan bahan baku ikan segar dan langsung dibeli dari nelayan yang baru pulang melaut

(Lokasi Pelabuhan Merah, Jl. Melati Desa Tanah Merah Kabupaten Indragiri Hilir
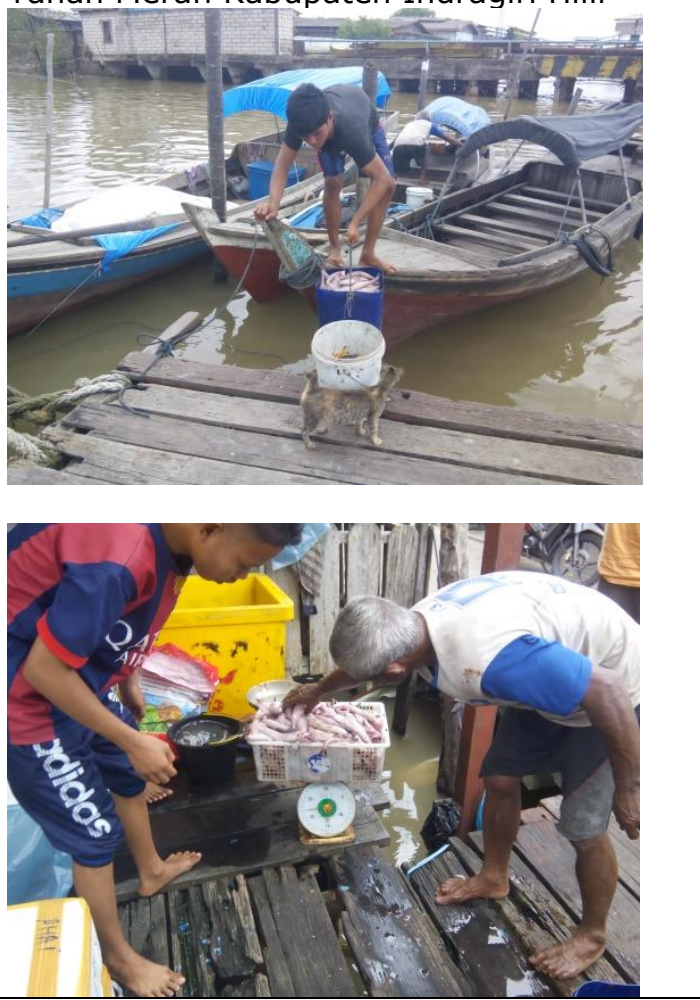